Archived version from NCDOCKS Institutional Repository http://libres.uncg.edu/ir/asu/

\title{
Appalachïan
}

B O O N E, N O R T H A R O L N A

\section{Does Rhetoric Impact Advertising Effectiveness With Liking Controlled?}

\author{
By: Bruce A. Huhmann and Pia A. Albinsson
}

\begin{abstract}
Purpose: Rhetorical works (schemes and tropes) can increase advertisement liking. Because liking impacts advertising effectiveness, this study aims to investigate if positive processing, brand awareness, and persuasion outcomes previously associated with rhetoric are spurious and chiefly attributable to liking. Design/methodology/ approach: An experiment $(n=448)$ employed natural advertising exposure conditions and a 3 (headline: nonfigurative, scheme, trope) $\times 2$ (copy length: long, moderate) $\times 2$ (involvement: high, low) between - subjects factorial design. Findings: Absent of liking differences, schemes and tropes are robust motivators of available resources devoted to processing (elaboration and readership). Favourable arguments only influence brand awareness and persuasion if processed. Consumers negatively view longer copy. Nonfigurative headlines encourage insufficient processing as copy lengthens. Insufficient processing decreases brand awareness and persuasion. However, schemes and tropes overcome negative copy length effects on brand awareness and persuasion regardless of involvement. Research limitations/implications: Without the benefit of increased liking, schemes interfere with copy point and brand memory similar to other creative attention - getters - humour and sex appeals. Instead, schemes focus consumers on advertising style. The results are based on consumer responses; thus, error may make differences harder to detect. Another limitation is the focus on a single low - risk, informational product, i.e. pens. Future research should investigate effects of rhetorical works with high - risk and transformative products. Practical implications: Advertisers should use rhetorical works to motivate processing, especially with longer copy explaining advantages of new, technical, or complex products. Also, effective rhetorical works need not create positive affect.
\end{abstract}

Bruce A. Huhmann, Pia A. Albinsson, (2012) "Does rhetoric impact advertising effectiveness with liking controlled?", European Journal of Marketing, Vol. 46 Issue: 11 / 12, pp.1476-1500, https:// doi.org/10.1 108/03090561211259943. Publisher version of record available at: https:// www.emeraldinsight.com/doi/full/10.1 108/03090561211259943 


\title{
Does rhetoric impact advertising effectiveness with liking controlled?
}

\author{
Bruce A. Huhmann \\ Department of Marketing, New Mexico State University, Las Cruces, \\ New Mexico, USA, and \\ Pia A. Albinsson \\ Department of Marketing, The Walker College of Business, Boone, \\ North Carolina, USA
}

\begin{abstract}
Purpose - Rhetorical works (schemes and tropes) can increase advertisement liking. Because liking impacts advertising effectiveness, this study aims to investigate if positive processing, brand awareness, and persuasion outcomes previously associated with rhetoric are spurious and chiefly attributable to liking.

Design/methodology/approach - An experiment $(n=448)$ employed natural advertising exposure conditions and a 3 (headline: nonfigurative, scheme, trope) $\times 2$ (copy length: long, moderate) $\times 2$ (involvement: high, low) between-subjects factorial design.

Findings - Absent of liking differences, schemes and tropes are robust motivators of available resources devoted to processing (elaboration and readership). Favourable arguments only influence brand awareness and persuasion if processed. Consumers negatively view longer copy. Nonfigurative headlines encourage insufficient processing as copy lengthens. Insufficient processing decreases brand awareness and persuasion. However, schemes and tropes overcome negative copy length effects on brand awareness and persuasion regardless of involvement.

Research limitations/implications - Without the benefit of increased liking, schemes interfere with copy point and brand memory similar to other creative attention-getters - humour and sex appeals. Instead, schemes focus consumers on advertising style. The results are based on consumer responses; thus, error may make differences harder to detect. Another limitation is the focus on a single low-risk, informational product, i.e. pens. Future research should investigate effects of rhetorical works with high-risk and transformative products.

Practical implications - Advertisers should use rhetorical works to motivate processing, especially with longer copy explaining advantages of new, technical, or complex products. Also, effective rhetorical works need not create positive affect.

Originality/value - Isolating advertising rhetoric effects from liking differences explains anomalies in the literature (e.g. scheme versus trope superiority).
\end{abstract}

Keywords Advertising rhetoric, Figurative language, Processing, Attitudes, Memory, Likeability, Content analysis, Consumer behaviour

Paper type Research paper

1. Introduction

"Makes crow's feet walk away" - CamoCare wrinkle reducer

Why advertise with a rhetorical headline instead of a more straightforward and concrete nonfigurative headline, such as "Reduces crow's feet"? Literal, concrete 
wording should increase attention, brand attitudes and intentions (Mitchell et al., 1994). Yet why do rhetorical headlines or taglines appear in almost 3/4 of all print ads (Leigh, 1994; McQuarrie and Mick, 1996)? One possibility is that rhetoric increases advertisement liking among consumers.

Rhetorical works have been thought to increase liking since Aristotle and Quintilian in classical antiquity. Rhetorical works includes verbal rhetorical figures (i.e. figurative language - alliteration, rhyme, hyperbole, puns, and metaphors) in headlines/copy and visual rhetoric, such as hyperbolic or metaphorical images. Rhetorical works create attention-directing word/image patterns or indirectly communicate meanings that recipients must infer (Huhmann, 2007). Liking can arise through pleasurable language sounds/patterns as with music or successfully deciphering nonliteral meanings (Mothersbaugh et al., 2002; Scott, 1990; Yorkston and Menon, 2004). Another explanation is incongruity. Successful incongruity resolution can produce positive affect or liking (e.g. Meyers-Levy and Tybout, 1989; Peracchio and Tybout, 1996). Rhetorical works exhibit resolvable incongruity in the arrangement or meaning of creative advertising elements (McQuarrie and Mick, 1996). Nonfigurative works do not exhibit incongruity, but express literal, straightforward meanings in typical, expected ways (e.g. "Sinus relief in under a minute").

Liking has a very powerful effect on processing, brand awareness, and persuasion. In fact, the Advertising Research Foundation found liking to be the strongest determinant of persuasion in its extensive Copy Research Validity Project and subsequent advertising research has established advertisement liking as the primary driver of advertising effectiveness (for a review, see Smits et al., 2006).

Thus, liking's influence on advertising effectiveness calls into question extant research linking rhetorical works with increased processing (e.g. Mothersbaugh et al., 2002), brand awareness (e.g. McQuarrie and Mick, 2003; Tom and Eves, 1999), and persuasion (e.g. DeRosia, 2008; Tom and Eves, 1999). These effects may spuriously arise from increased liking associated with rhetorical compared to nonfigurative works. Many studies have shown greater liking, such as advertisement likeability $\left(\mathrm{L}_{\mathrm{ad}}\right)$ or attitude toward the advertisement $\left(\mathrm{A}_{\mathrm{ad}}\right)$, with rhetorical versus nonfigurative works (see Table I). With liking held constant between nonfigurative and rhetorical works, the increased processing, brand awareness, and persuasion associated with advertising rhetoric in earlier studies may be mitigated. In fact, nonfigurative works may perform better without rhetorical works' benefits from increased liking.

Alternatively, liking due to harmonious-sounding patterns or successful incongruity resolution may not solely explain advertising effectiveness differences. Rhetorical works have not consistently been found to enhance liking compared to nonfigurative works (e.g. Gregan-Paxton et al., 2002; Ketelaar et al., 2007; McQuarrie and Mick, 2009; van Enschot et al., 2008; Warlaumont, 1995). Other properties that may influence advertising effectiveness include artful deviance, meaning openness, and resource demand. Artful deviance of a rhetorical work marks an advertising element; so, readers note it and use surrounding context for interpretation (McQuarrie and Mick, 1999). Meaning openness refers to the polysemious (i.e. multiple meanings), uncertain, or ambiguous interpretation of rhetorical works (Mothersbaugh et al., 2002). Resource demand, like cognitive load, is the amount of resources required to process successfully. It is a function of incongruity, novelty, complexity and semantic conflict (Bettman et al., 1998; Huhmann, 2007; Larsen et al., 2004). 
Table I.

Processing, brand awareness and persuasion results of prior research
Outcome Main effects

Studies documenting greater liking with rhetorical than nonfigurative works

Processing Elaboration greater with rhetorical than nonfigurative works, measured by self ratings (Dingena, 1994; Jeong, 2008) and CRs (McQuarrie and Mick, 2009; Nelson and Hitchon, 1999)

Readership greater with rhetorical than nonfigurative works, measured by aided message recall (McQuarrie and Mick, 1992, 2003, 2009)

Advertisement-style CRs are more numerous and more positively valenced with trope than nonfigurative works (McQuarrie and Mick, 2009; Stafford et al., 1996)

Persuasion Persuasion greater with rhetorical than nonfigurative works, measured by $A_{b}$ (Brennan and Bahn, 2006; Jeong, 2008; McQuarrie and Mick, 1992; Stafford et al., 1996) and purchase intentions (Jeong, 2008; Stafford et al., 1996)

Liking not measured nor controlled

Processing Elaboration, measured by CRs, greater with nonfigurative than rhetorical works (Mitchell et al., 1994) or the same across nonfigurative and rhetorical works (Pawlowski et al., 1998)

Readership greater with rhetorical than nonfigurative works, measured by self ratings (Huhmann et al., 2002), Starch Read Most scores (Mothersbaugh et al., 2002), and message recall (Ahluwalia and Burnkrant, 2004; Leong et al., 2000; Munch et al., 1993) Readership, measured by message recall, greater with nonfigurative than rhetorical works (Hayes et al., 1982) or the same across nonfigurative and rhetorical works (Mitchell et al., 1994)

More advertisement-style CRs for print ads with scheme than trope and trope than nonfigurative headlines (Mothersbaugh et al., 2002)

Brand Brand awareness greater with rhetorical than nonfigurative works, measured by Gallup awareness \& Robinson Proved Name Registration scores (Tom and Eves, 1999), brand recall (Gray and Snyder, 1989; MacLachlan and Jalan, 1985), and brand name recognition (Leong et al., 2000)

Brand awareness the same across nonfigurative and rhetorical works, measured by brand recall (Mitchell et al., 1994; Pawlowski et al., 1998)

Persuasion Persuasion greater with rhetorical than nonfigurative works, measured by $\mathrm{A}_{b}$ (Hitchon, 1997), attitude change (Bowers and Osborn, 1966), and Gallup \& Robinson Favorable Buying Attitude scores (Tom and Eves, 1999)

Persuasion the same across nonfigurative and rhetorical works, measured by $A_{b}$ (Ahluwalia and Burnkrant, 2004; Munch et al., 1993) and attitude change (Bosman and Hagendoorn, 1991)

This study's purpose entails determining whether rhetorical works produce any effects beyond those attributable to increased liking by controlling positive affect/liking across rhetorical and nonfigurative conditions. If rhetorical works do not have effects beyond liking, practitioners should view them merely as another means of increasing liking and should pre-test liking associated with rhetorical works to avoid ineffectual advertising. But if rhetorical works produce processing, brand awareness, and persuasion effects without increased liking, this study will determine how these effects differ from those found in studies in which increased positive affect was associated with rhetorical rather than nonfigurative works (see Table I). By extending research, our contribution is a richer understanding of rhetorical works' role in advertising effectiveness beyond that attributable to liking. 


\section{Rhetorical works}

Writing, images/art, and music rely on learnt conventions or expectations (Scott, 1990, 1994; Scott and Vargas, 2007). Rhetorical works violate these conventions with artfully deviant, incongruent creative executions, such as visual rhetoric and verbal rhetorical figures in headlines or copy (McQuarrie and Mick, 1996). Visual rhetoric violates pictorial conventions. For example, a woman without a mouth in a female voting advocacy advertisement or a car morphed with a face illustrating the intelligence of buying Saab (Messaris, 1997). With verbal rhetorical figures, schemes violate typical, non-repetitive language conventions with sound or word patterns that create surface incongruity (Mothersbaugh et al., 2002). Arrangements can be as important as arguments in persuasion (Scott, 1994). For example, rhymes repeat end sounds, such as "Lunchable's "Balanced Fuel That's Cool" or "To save and invest, talk to NatWest." Word-pattern schemes repeat words, such as Ritz Crackerfuls' "Real cheese. Real whole grain. Real delicious." or reverse/oppose words, such as 7-Up's "You like it. It likes you." Schemes break language's monotony, forcing recipients to stop, think, and notice what is being communicated. Scheme's surface incongruity is stylistic; it does not alter word meanings or make recipients infer implicit meanings as tropes do. Tropes create semantic incongruity by violating conventions that communication is explicit and means what it says. Tropes require recipients to infer advertisers' implicit interpretations by substituting what is meant for what is said, appreciating multiple meanings, or seeing connections between objects. For example, metaphors modify meaning by equating objects from different domains (e.g. "Scope is Aromatherapy for Couples" or "Happiness is a cigar called Hamlet"). Puns elicit multiple meanings with the same word (e.g. "happy" in Nature Made's “Are you happy with your St John's Wort?" brings to mind both the product's depression-alleviating properties and product satisfaction). With hyperbole, recipients substitute intended for exaggerated meanings (e.g. Subaru's "Clings to a surface so well you'll swear you have superpowers" should create inferences about Subaru's handling not its ability to confer actual superpowers on drivers). Semantic incongruity is both quantitatively greater as well as qualitatively different than surface incongruity (Mothersbaugh et al, 2002). Although tropes' meanings are implicit, consumers successfully decipher them (Ma, 2008; McQuarrie and Mick, 1999). This occurs because advertisers craft rhetorical works based on recipients' probable knowledge, experiences, and cultural conventions (Scott, 1994).

Thus, tropes possess more incongruity than schemes and both verbal rhetorical works (schemes and tropes) possess more incongruity than nonfigurative works, which express literal, straightforward meanings in typical, expected ways without incongruous sound/word patterns or meanings, such as Bose headphones' "Quieter than ever before" (e.g. McQuarrie and Mick, 1996; Mothersbaugh et al., 2002).

However, Scott (1990, p. 228) remarks, "Ads, like sentences, symphonies, and sculptures, vary in quality and impact." For example, only one of Gregan-Paxton et al.'s (2002) trope manipulations increased liking over the nonfigurative version, the other did not. Also, greater incongruity does not always elicit more positive affect. Some studies document exceptions to the linear incongruity-liking relationship (e.g. McQuarrie and Mick, 2009; van Enschot et al., 2008; Warlaumont, 1995). Incongruity theory actually suggests an inverted-U function where at some point greater incongruity decreases liking (Meyers-Levy and Tybout, 1989; Peracchio and Tybout, 1996). The resource matching perspective theoretically explains this curvilinear relationship. 


\section{Resource-matching perspective}

Once liking is controlled, the resource-matching perspective should explain rhetorical works' effect on advertising processing and its outcomes given the limited cognitive resources consumers are willing and able to devote. The resource-matching perspective holds that processing approaches optimization as resource demand better matches available cognitive resources. Resource demand exceeding available resources produces information overload. Available resources exceeding resource demand impairs processing through tedium/boredom or distraction by more engaging stimuli (Anand and Sternthal, 1990; Larsen et al., 2004).

Rhetorical works create greater resource demand than nonfigurative works (DeRosia, 2008). Because rhetorical works' resource demand is a function of incongruity, novelty, conflict, and complexity, tropes should exhibit greater resource demand than schemes (Huhmann, 2007). As demand surpasses available resources, processing deteriorates. For example, in a resource-demanding context (evaluating numerous advertisements), moderate resource-demand schemes outperform higher resource-demand tropes (van Enschot et al., 2008). This supports the inverted U-shaped relationship between processing and structural properties discussed in experimental aesthetics (Huhmann, 2007).

Because conventions/expectations are learnt, research has documented differences in advertising effectiveness associated with rhetorical works between children versus adults, experts versus novices, members versus outsiders in cultures (Scott and Vargas, 2007). The lack of experience/prior knowledge of children, novices, or strangers/foreigners should increase resource demand associated with processing (Huhmann, 2007). Advertising rhetoric studies have documented differences due to age (i.e. children versus adults; Hayes et al., 1982), persuasion knowledge (Ahluwalia and Burnkrant, 2004), expertise (Roehm and Sternthal, 2001), and knowledge of language or cultural conventions (Leong et al., 2000; Ma, 2008; McQuarrie and Mick, 1999; Mothersbaugh et al., 2002).

Advertising executions also alter resource demand. Print advertising copy length negatively impacts processing (e.g. Diamond, 1968; Huhmann et al., 2002; Starch, 1966). Increased resource demand explains Starch's (1966) finding that increasing copy length decreased "Read Most" scores. Similar results are documented with TV commercial length (Smits et al., 2006).

Consumers are cognitive misers who minimize cognitive effort unless intrinsically or extrinsically encouraged to boost available resources (Bettman et al., 1998; Fiske and Taylor, 1991). Advertising properties, such as meaning openness, can extrinsically influence available resources. Meaning openness (aka, polysemy/ambiguity) increases from nonfigurative to scheme to trope (McQuarrie and Mick, 1992; Mothersbaugh et al., 2002; Huhmann, 2007; Warlaumont, 1995). Research suggests that rhetoric's meaning openness motivates consumers to boost available resources devoted to advertisement processing compared with nonfigurative works. Processing measures - Starch "Read Most" scores and cognitive responses (CRs) - increase with meaning openness ratings from nonfigurative to scheme to trope (Mothersbaugh et al., 2002; Nelson and Hitchon, 1999).

Consumers' intrinsic or extrinsic motivation also affects available resources. Need for cognition (NFC) intrinsically motivates available resources. DeRosia (2008) found a curvilinear relationship with a visual trope exemplifying the resource 
demand/availability function. Advertising effectiveness peaked with moderate NFC, but declined with lower (cognitive overload) and higher NFC (tedium). Comparing nonfigurative to trope copy, Brennan and Bahn (2006) found improved brand attitudes $\left(A_{b}\right)$ and message CRs for highly resource-demanding trope copy only when high NFC sufficiently motivated available resources. Finally, Roehm and Sternthal's (2001) finding that high-NFC subjects better comprehend rhetorical advertisements but low-NFC subjects better comprehend nonfigurative advertisements supports optimized processing when available resources match demand.

Advertising involvement, or a message's personal relevance, extrinsically motivates available resources. Higher involvement increases intensive brand information processing over lower involvement (Celsi and Olson, 1988; Miniard et al., 1990; Petty et al., 1983).

\section{Hypotheses}

To investigate rhetorical works' processing, brand awareness, and persuasion effects independent of liking, this study compares prior results with results when liking is constant across nonfigurative, scheme, and trope conditions. Studies finding more positive affect with rhetorical than nonfigurative works consistently document greater processing, brand awareness, and persuasion with rhetorical than nonfigurative works (see Table I).

Inconsistent effects appear in studies finding negative affect-rhetoric relationships. With scheme headlines eliciting greater liking than nonfigurative versions, but trope headlines without increased liking over nonfigurative versions, McQuarrie and Mick (2009) found more CRs and recall with schemes but not tropes. Gregan-Paxton et al. (2002) found lower recall with trope than nonfigurative product descriptions despite one trope eliciting greater liking than the nonfigurative and one not. However, Warlaumont (1995) found increased recall despite less liking with rhetorical visuals.

Studies neither measuring nor controlling liking between rhetorical and nonfigurative works also exhibit inconsistent results. Some find greater processing, brand awareness, and persuasion with rhetorical than nonfigurative works. Others find the opposite. Yet others find no difference (see Table I).

Because liking influences advertising effectiveness (Bergkvist and Rossiter, 2008; MacKenzie and Lutz, 1989; Smits et al., 2006), controlling liking should eliminate differences between rhetorical and nonfigurative works if liking is responsible for those differences. Thus, the null hypothesis is that no main effect of headline condition (nonfigurative versus scheme versus trope) should be observed when liking is held constant.

H1. With liking controlled, nonfigurative and rhetorical (scheme or trope) headlines will lead to similar processing, brand awareness, and persuasion.

Predictions based on the resource-matching perspective take into account copy length's resource demand and available resources motivated by involvement. Processing, awareness, and persuasion should deteriorate as resource demand rises above available resources, but improve as available resources match demand.

Consumers view longer copy more negatively than shorter copy (Huhmann et al., 2002; Starch, 1966). Thus, copy length should inversely relate to liking; thus, processing, awareness, and persuasion should decline as copy lengthens. This should 
especially occur with lower involvement and creative advertising elements that insufficiently boost available resources. Advertising effectiveness depends on positive or negative associations present during exposure when motivation to devote available resources is low if measures, as in the current study, provide a brand context (Grimes, 2008). Rhetorical works appear to boost available resources (McQuarrie and Mick, 1996; Mothersbaugh et al., 2002), but that may be an artefact of liking. The null hypothesis holds that removing liking differences between headline conditions inhibits rhetorical works' moderating influence on the relationship between resource-demand altering executional/mechanical elements and advertising effectiveness.

H2. With liking controlled, nonfigurative and rhetorical headlines should not moderate copy length's inverse relationship with processing, brand awareness, or persuasion.

Higher-involvement consumers make sufficient resources available to seek out and elaborate on an advertisement's brand information, but lower-involvement consumers make fewer resources available and focus on less resource-demanding executional/mechanical elements, such as bright colours, catchy phrases, and attractive models (MacKenzie and Lutz, 1989; Miniard et al., 1990; Petty et al., 1983). Under lower involvement, peripheral cues can enhance awareness and persuasion, or creative elements that encourage processing favourable brand information enhances persuasion (Olson and Thjømøe, 2003). Research documenting greater liking with rhetorical compared to nonfigurative works also demonstrates greater processing and persuasion with rhetorical than nonfigurative works under lower involvement but not higher involvement (e.g. Toncar and Munch, 2001). Thus, if liking is responsible for rhetorical works moderating the involvement-advertising effectiveness relationship, the null hypothesis holds that removing liking differences inhibits moderation.

H3. With liking controlled, nonfigurative and rhetorical headlines should not interact with involvement on processing, brand awareness, or persuasion.

\section{Method}

\section{Participants and procedure}

An experiment using a 3 (headline: nonfigurative, scheme, trope) $\times 2$ (copy length: long, moderate) $\times 2$ (involvement: high, low) between-subjects factorial experimental design was employed. Besides manipulations, all target advertisement executional elements (illustration, layout, type size, font, and brand information) remained constant across conditions. In 20-person groups, 480 students from a US university participated and were debriefed.

Using established procedures for studying rhetorical processing under natural advertising exposure conditions, the target advertisement appeared in a magazine geared towards college students (e.g. Huhmann et al., 2002; McQuarrie and Mick, 2003, 2009; Mothersbaugh et al., 2002). To disguise the purpose, a cover story instructed participants that a publisher was interested in the time spent with different magazine components (articles, editorials, and advertisements). Later, participants indicated the study's supposed purpose to assess experimental demand. Participants listing purposes similar to hypotheses or manipulations were eliminated. Because language difficulties increase resource demand, participants whose first language was not 
English were dropped following McQuarrie and Mick (1999) and Mothersbaugh et al. (2002), leaving 448 for analysis.

Participants were encouraged to spend as long or as little time as they wanted. The magazine contained three articles and seven full or half page advertisements for student-relevant products. A questionnaire immediately followed the target advertisement. First, participants were asked to "list all thoughts, ideas, images, or reactions you had while looking at the last ad" then indicate if each cognitive response (CR) was positive, negative, or neutral. Two judges later coded CRs as related to advertisement style $\left(\mathrm{CRs}_{\mathrm{ad}}\right)$ or message $\left(\mathrm{CRs}_{\text {mess }}\right)$, or other/irrelevant (Brennan and Bahn, 2006; Celsi and Olson, 1988; Miniard et al., 1990; Mothersbaugh et al., 2002; Stafford et al., 1996). Agreement was high $\left(\mathrm{CRs}_{\mathrm{ad}}=94\right.$ percent; $\mathrm{CRs}_{\mathrm{mess}}=84$ percent; other/irrelevant $=83$ percent); discussion resolved disagreements.

\section{Stimuli}

The advertised product - pens - helped achieve comparability with earlier studies (e.g. DeRosia, 2008; Huhmann et al., 2002; Mothersbaugh et al., 2002). Problem-solution formats (e.g. normal depletion) are appropriate when advertising informational products. The advertised brand solves pen problems of rapid depletion or inconveniently running out of ink during exams or note-taking. Illustrations impact persuasion less with informational products (Rossiter and Bellman, 2005), strengthening the copy processing-persuasion relationship.

Rhetorical works: Following prior research (e.g. Huhmann et al., 2002; McQuarrie and Mick, 2003, 2009; Mothersbaugh et al., 2002), a print advertisement's headline was manipulated. To enhance generalizability across rhetorical works, the headline manipulation used multiple nonfigurative, scheme and trope headlines. These same headlines had successfully manipulated headline conditions with equivalent meanings in Huhmann et al. (2002). They report that incongruity increased from nonfigurative to scheme to trope. Also, their 26 pretest participants read all headlines and indicated agreement (agree $=1$, disagree $=9$ ) with "All the headlines are basically communicating the message that Bingley Pens hold more ink." Responses near the endpoint $(M=2.0$; sd $=0.37)$ verified all headlines communicated similar meanings.

Copy length: Both copy length versions (moderate, 75 words; long, 218 words) contained equivalent copy points. Both versions were taken from Huhmann et al. (2002). Their 26 pretest participants read both copy length versions, then indicated agreement (agree $=1$, disagree $=9$ ) with "Other than one version being shorter than the other, the two ad copy versions communicate the same basic information." Responses near the endpoint $(M=2.35$, sd $=0.47)$ verified communication of similar brand information.

Involvement: The previously used manipulation told higher-involvement participants that they would choose one of the two pens advertised in the magazine at the session's end and that advertised products would be available in their area soon. Lower-involvement participants were told they would choose from two brands of candy advertised in the magazine, but that advertised brands would not be available in their area any time soon (e.g. Celsi and Olson, 1988; Huhmann et al., 2002; Miniard et al., 1990; Munch et al., 1993; Petty et al., 1983). 


\section{Manipulation checks}

The involvement manipulation was checked via total number of cognitive responses (Celsi and Olson, 1988; Toncar and Munch, 2001). Manipulation checks verified that rhetorical properties - artful deviance, resource demand, and meaning openness increased from nonfigurative to scheme to trope, but that liking remained consistent across headline conditions. McQuarrie and Mick's (1996) nine-point artful deviance scale has endpoints of "artful/clever" versus "straightforward/matter-of-fact."

Resource demand/cognitive load arise from perceived incongruity, complexity, conflict, and novelty (Bettman et al., 1998; Huhmann, 2007; Larsen et al., 2004). Thus, we developed a formative measure assessing resource demand via nine-point semantic differential scale indicators with endpoints of "typical/not typical," "simple/complex," "not conflict-inducing/conflict-inducing," and "expected/unexpected," following "I found the headline [...]" Average scores were calculated. All items had loadings greater than 0.72 on the resource demand component in a principal component analysis, which considers unique and common variance. Internal reliability (coefficient alpha) is inappropriate with formative measures.

Meaning openness scores were averaged from Mothersbaugh et al.'s (2002) scale. Three nine-point reflective indicators measured agreement with "I had to use my imagination to interpret this headline," "the headline invited me to participate in generating a meaning," and "I had to work to interpret this headline." Items evinced adequate reliability (coefficient alpha $=0.75$ ), comparable to Mothersbaugh et al.'s (2002) coefficient alpha of 0.71.

Liking was assessed three ways. A pretest and the main study measured $\mathrm{L}_{\mathrm{ad}}$ and headline liking. A single-item $\mathrm{L}_{\mathrm{ad}}$ scale recommended by Bergkvist and Rossiter (2008) used a nine-point semantic differential anchored by "like very much/dislike very much." Headline liking was measured via three nine-point semantic differential scales anchored by "bad/good," "dislikeable/likeable," and "unfavourable/favourable" following "This headline is...." The main study also subtracted the number of negative from positive $\mathrm{CRS}_{\mathrm{ad}}$ following Stafford et al. (1996), who measured affect associated with rhetorical works via valanced $\mathrm{CRS}_{\mathrm{ad}}$.

\section{Dependent measures}

Processing includes elaboration and readership measures. Elaboration measures are total $\mathrm{CRs}_{\text {mess }}$ and rated processing. Rated processing used nine-point semantic differential scales anchored by "very uninvolved/very involved," "concentrating very little/concentrating very hard," and "paying very little attention/paying a lot of attention" followed "While looking at the last ad, I was [...]" A fourth reversed item measured agreement with "I carefully considered the claims about the brand in the last ad." Items were averaged due to acceptable reliability (coefficient alpha $=0.86$ ), comparable to coefficient alpha of 0.91 reported by Miniard et al. (1990), who used this measure to assess advertisement processing associated with message involvement.

Readership measures include copy-point recognition and approximate number of words of copy read. Copy-point recognition listed seven brand features; three were in the target advertisement's copy. Remaining features were credible for pen advertisements, but not in the target advertisement. Subjects indicated whether they saw, did not see, or were unsure if the brand feature was in the target advertisement. False copy-point recognition (i.e. failed to recognize actual brand features or claimed to 
recognize false features) was subtracted from true copy-point recognition (i.e. recognized actual features or rejected false features). Copy-point recognition ranged from a maximum score of 3 to a minimum score of -4 . Participants read a sample paragraph of 201 words to assess general reading speed. In line with the cover story, we recorded time spent on each magazine page. Words read were approximated by dividing time spent on the target advertisement by reading speed.

Brand awareness measures include unaided brand recall and brand-recall-boosted brand recognition (BRBBR). Rhetorical works have previously been shown to increase brand awareness using brand recall, brand recognition, and copy-testing scores (e.g. Gray and Snyder, 1989; Leong et al., 2000; Tom and Eves, 1999), but BRBBR best represents brand awareness needed to influence purchases of items sold in crowded retail displays where consumers must first recall the target brand on entering the store, then recognize the brand in an aisle or display (Rossiter and Bellman, 2005). Typical office supply stores carry large pen selections; thus, BRBBR best reflects pen brand search and choice. First, participants listed all advertised brands remembered from the magazine. Brand recall was coded as "1" if participants listed the target advertisement's brand. Later, participants identified ballpoint pen brands including the two advertised in the magazine. BRBBR was coded as a "1" if a participant both recalled and recognized the target advertisement's brand and "0" otherwise.

Persuasion measures include brand attitude $\left(\mathrm{A}_{\mathrm{b}}\right)$ and brand action intentions (BAI). Following Toncar and Munch (2001) and Brennan and Bahn (2006), $A_{b}$ was gauged by three nine-point semantic differential scale indicators: "favourable/unfavourable," "good/bad," and "likeable/dislikeable." Indicators were averaged due to acceptable reliability (coefficient alpha $=0.95$ ). Following Rossiter and Bellman (2005), BAI measured predicted incidence of actual purchase by four weighted options following "If Bingley Pens were available in stores in your area, do you think you would buy it?": "would not buy" (0), "might buy" (0.1), "probably will buy" (0.4), and "definitely will buy" (0.9).

\section{Results}

A pretest verified consistent headline liking across headline conditions $\left(F_{2,146}=0.133\right.$; $\mathrm{ns})$. It also verified similar $\mathrm{L}_{\mathrm{ad}}$ across nonfigurative, scheme, and trope headlines when embedded in the moderate copy advertisement version $\left(F_{2,146}=0.169\right.$; ns). Thus, the main study should be able to investigate headline effects absent liking differences.

Manipulation checks in the main study confirmed pretest results of similar liking across headline conditions ( $\mathrm{L}_{\mathrm{ad}}: F_{2,445}=0.763$, ns; headline liking; $F_{2,445}=0.133$, ns; valenced $\mathrm{CRs}_{\mathrm{ad}}: F_{2,445}=0.226$; ns), but expected differences across headline conditions in other rhetorical properties; artful deviance $\left(F_{2,444}=22.422 ; p<0.001\right)$, resource demand $\left(F_{2,444}=27.516 ; p<0.001\right)$ and meaning openness $\left(F_{2,444}=27.516 ; p<0.001\right)$. Post-hoc mean tests using Fisher's least significant difference procedure show that:

- nonfigurative headlines exhibit less artful deviance $(M=3.21)$ than schemes $(M=4.39)$ or tropes $(M=6.93)$ and schemes exhibit less artful deviance than tropes (all $p$ 's $<0.001$ );

- nonfiguratives create less resource demand $(M=3.99)$ than schemes $(M=4.33)$ or tropes $(M=4.99)$ and schemes create less resource demand than tropes (all $p$ 's $<0.021)$; and 
- nonfiguratives engender less meaning openness $(M=3.17)$ than schemes $(M=3.68)$ or tropes $(M=4.63)$ and schemes engender less meaning openness than tropes (all $p$ 's $<0.035$ ).

Total CRs checked the involvement manipulation. They were greater under higher $(M=3.57)$ than lower involvement $\left(M=3.11 ; F_{1,446}=7.071 ; p<0.01\right)$. Further, many processing dependent variables showed expected involvement main effects (see Table II). Consistent with Miniard et al. (1990) and Celsi and Olson (1988), participants also reported more $\mathrm{CRS}_{\text {mess }}$ under higher $(M=2.24)$ than lower involvement ( $M=1.72$ ). Similarly, rated processing (higher: $M=4.94$, lower: $M=3.93$ ), copy-point recognition (higher: $M=2.09$, lower: $M=1.20$ ), and words read (higher: $M=94.73$, lower: $M=75.33$ ) reflected expected involvement main effects.

Main study. Multivariate analyses of variance (MANOVAs) were conducted on processing variables, then brand awareness/persuasion variables. Tables II and III report multivariate and univariate results.

Null H1 predicts no headline main effect on processing, brand awareness, or persuasion absent liking differences. As shown in Tables II and III, H1a is rejected for processing, but not $H 1 b$ (brand awareness) or $H 1 c$ (persuasion).

Follow-up contrasts reveal that, when liking is controlled, both rhetorical headline types (schemes and tropes) outperform nonfigurative headlines on two processing variables. Rated processing is lower for nonfigurative $(M=3.91)$ than schemes $\left(M=4.66 ; F_{\text {contrast }}=11.49, p<0.001\right)$ or tropes $\left(M=4.52 ; F_{\text {contrast }}=7.91, p<0.005\right)$. Similarly, words read is less for nonfigurative $(M=66.52)$ than schemes $(M=88.12$; $\left.F_{\text {contrast }}=8.97, p<0.005\right)$ or tropes $\left(M=92.89 ; F_{\text {contrast }}=13.72, p<0.001\right)$. No scheme-trope difference emerged in rated processing or words read $\left(F_{\text {contrast }}\right.$ 's $<0.57$, ns).

Schemes $(M=1.73)$ outperform tropes $\left(M=1.13 ; F_{\text {contrast }}=14.71, p<0.001\right)$ and nonfigurative headlines on $\mathrm{CRs}_{\mathrm{ad}}\left(M=1.19 ; F_{\text {contrast }}=8.94, p<0.005\right)$ with no difference between nonfiguratives and tropes $\left(M=1.13 ; F_{\text {contrast }}=0.15, \mathrm{~ns}\right)$.

$\mathrm{CRs}_{\text {mess }}$ and copy-point recognition do not differ between rhetorical and nonfigurative headlines $\left(F_{\text {contrast }}\right.$ 's $\left.<3.02, n s\right)$, but were greater with tropes $\left(\mathrm{CRs}_{\text {mess }}\right.$ : $M=2.30$; recognition: $M=2.06$ ) than schemes (CRs mess: $M=1.62$; recognition: $M=1.26 ; F_{\text {contrast }}$ 's $>7.94, p$ 's $\left.<0.005\right)$. These main effects are also superseded by interactions with copy length and involvement.

Null H2 predicts no interaction of headline condition with copy length, whereas null H3 predicts no interaction of headline condition with involvement, once liking differences are controlled. A headline by length by involvement interaction leads to $H 2 a$ and $H 3 a$ 's rejection for elaboration-related processing variables (rated processing and $\mathrm{CRs}_{\text {mess }}$ ), whereas headline by length interactions lead to $H 2$ 's rejection for readership-related processing variables (words read and copy-point recognition), brand awareness, and persuasion.

Follow-up contrasts for three-way interactions on elaboration-related processing variables reveal no copy length effect under lower involvement. $\mathrm{CRs}_{\text {mess }}$ between nonfigurative and rhetorical headlines under lower involvement is similar across copy lengths $\left(F_{\text {contrast }}\right.$ 's $<3.00$, ns). Rated processing is also similar across copy lengths $\left(F_{\text {contrast }}\right.$ 's $<1.11$, ns), but headline differences consistent with prior research were observed. Lower-involvement participants rated processing higher for trope than 


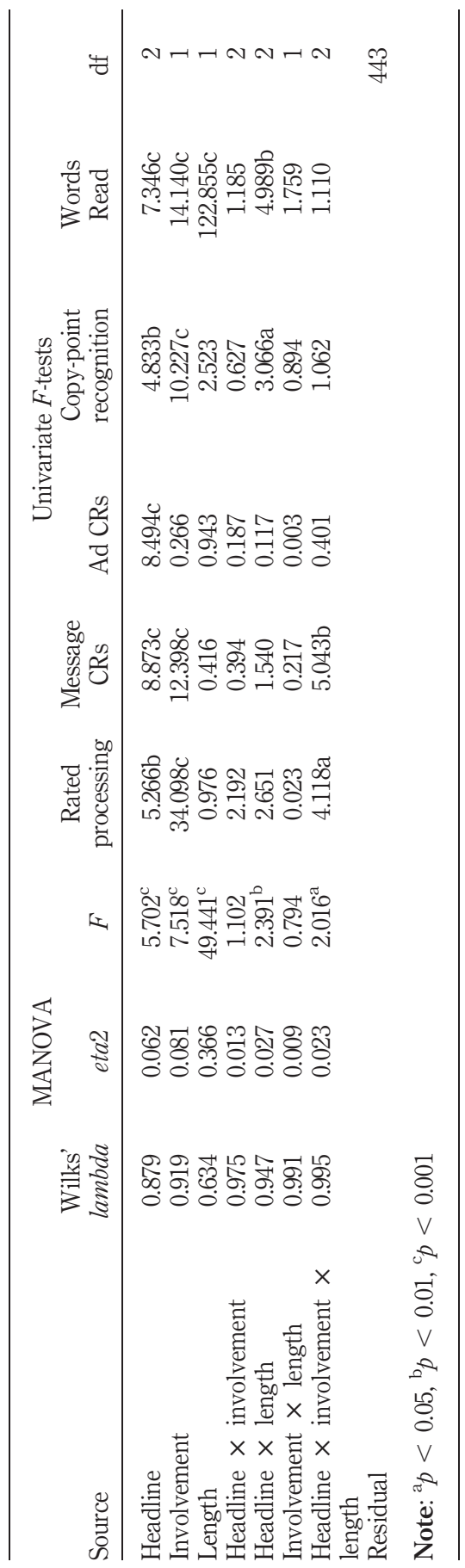

Table II.

Depth of processing results - elaboration, advertisement element thoughts, and readership 


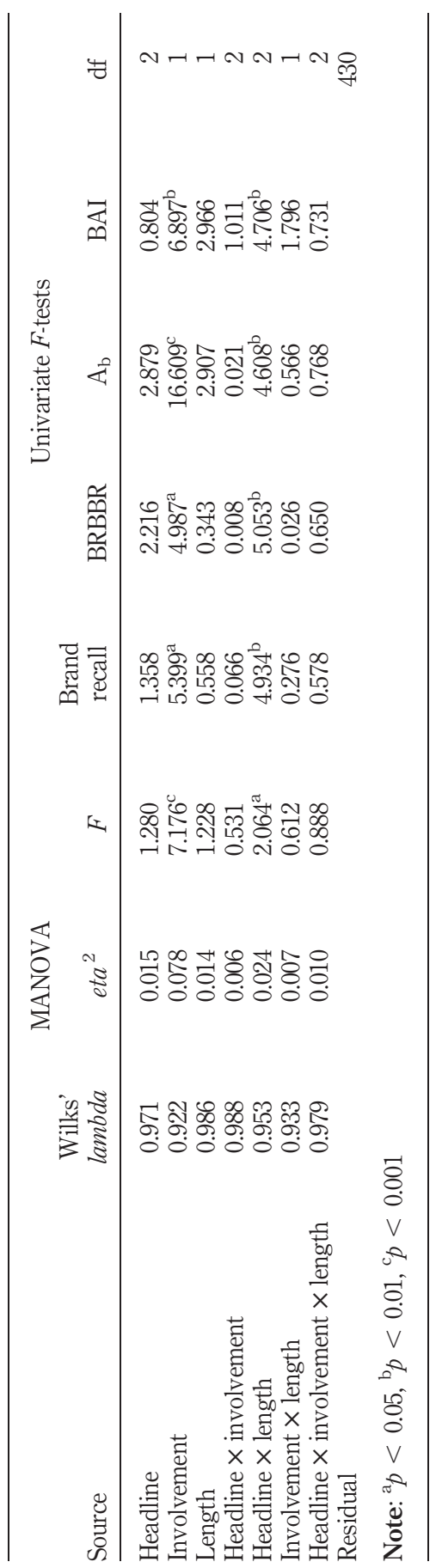

Table III.

Brand awareness and persuasion results 
nonfigurative headlines with moderate $\left(F_{\text {contrast }}=4.32, p<.05\right)$ and long copy $\left(F_{\text {contrast }}=4.11, p<0.05\right)$. No other copy length differences were evident under lower involvement.

Higher-involvement participants rated processing higher with moderate than long copy when exposed to nonfigurative headlines $\left(F_{\text {contrast }}=9.73, p<0.005\right)$, but similarly across copy length for scheme $\left(F_{\text {contrast }}=1.07, \mathrm{~ns}\right)$ and trope headlines $\left(F_{\text {contrast }}=2.91\right.$, $n s)$. Subsequent analyses also show similar rated processing across headline conditions with moderate copy $\left(F_{\text {contrast }}\right.$ 's $\left.<3.09, n s\right)$. However, with long copy, participants rated processing lower when exposed to nonfigurative than scheme $\left(F_{\text {contrast }}=16.72, p\right.$ $<0.001)$ or trope headlines $\left(F_{\text {contrast }}=10.39, p<0.005\right)$. $\mathrm{CR}_{\text {mess }}$ between nonfigurative or rhetorical headlines under higher involvement are similar across copy lengths $\left(F_{\text {contrast }}\right.$ 's $<2.19$, ns). However, subsequent analyses reveal greater $\mathrm{CRs}_{\text {mess }}$ under higher involvement when moderate copy was paired with tropes $(M=2.49)$ versus schemes $\left(M=1.51 ; F_{\text {contrast }}=7.24, p<0.01\right)$, but no other differences.

Table II reports headline by length interactions on readership-related processing variables. Follow-up contrasts reveal that lengthening copy decreases copy-point recognition for nonfigurative headlines $\left(F_{\text {contrast }}=4.07, p<0.05\right)$, but not schemes $\left(F_{\text {contrast }}=1.36\right.$; ns $)$ or tropes $\left(F_{\text {contrast }}=0.76\right.$; ns; see Figure 1$)$. Copy-point recognition is lower with scheme than nonfigurative $\left(F_{\text {contrast }}=5.19, p<0.05\right)$ or trope headlines $\left(F_{\text {contrast }}=12.93, p<0.001\right)$ with moderate copy. With long copy, however, copy-point recognition is similar across headline conditions ( $F_{\text {contrast }}$ 's $<1.20$; ns). Words read also decreases as copy lengthens for nonfigurative but not rhetorical headlines. Although Figure 2 shows more words read with long than moderate copy for

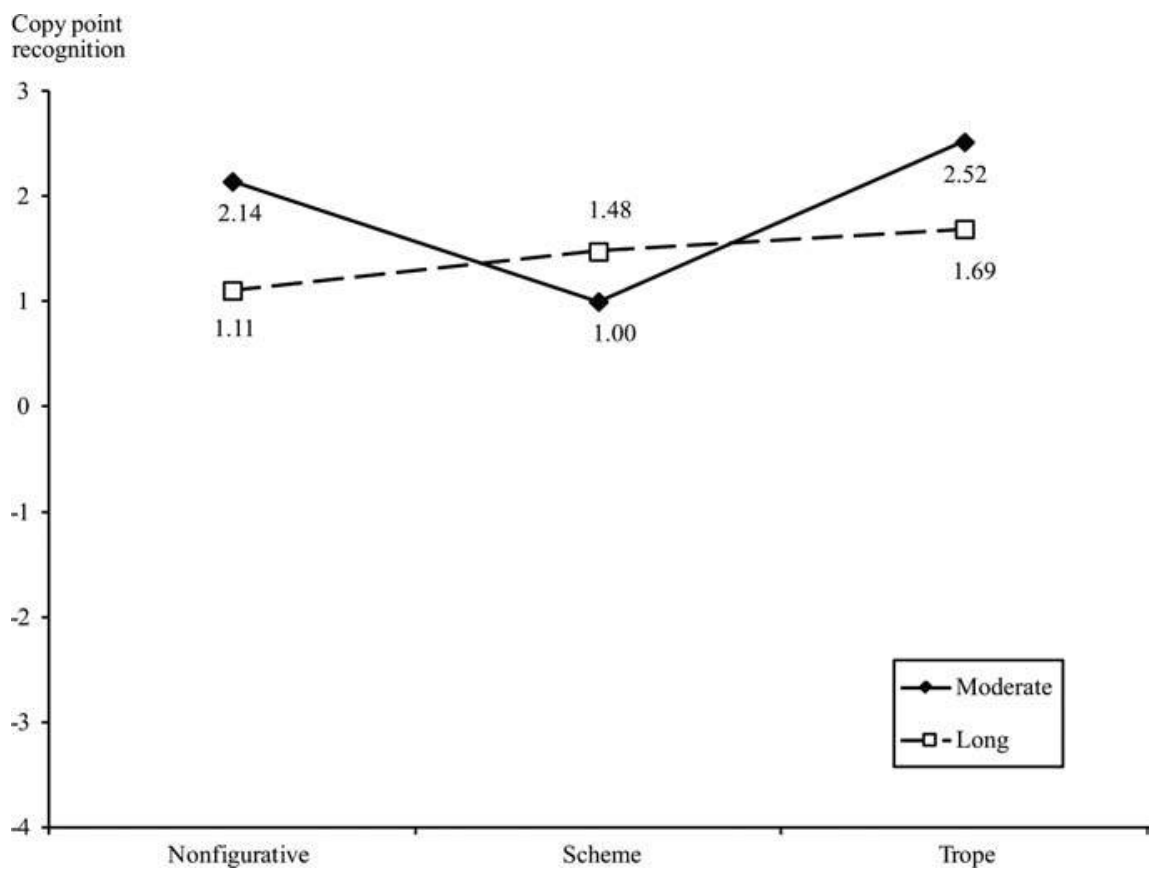

Figure 1.

Headline by copy length interaction on copy point recognition 
Figure 2.

Headline by copy length interaction on number of words read

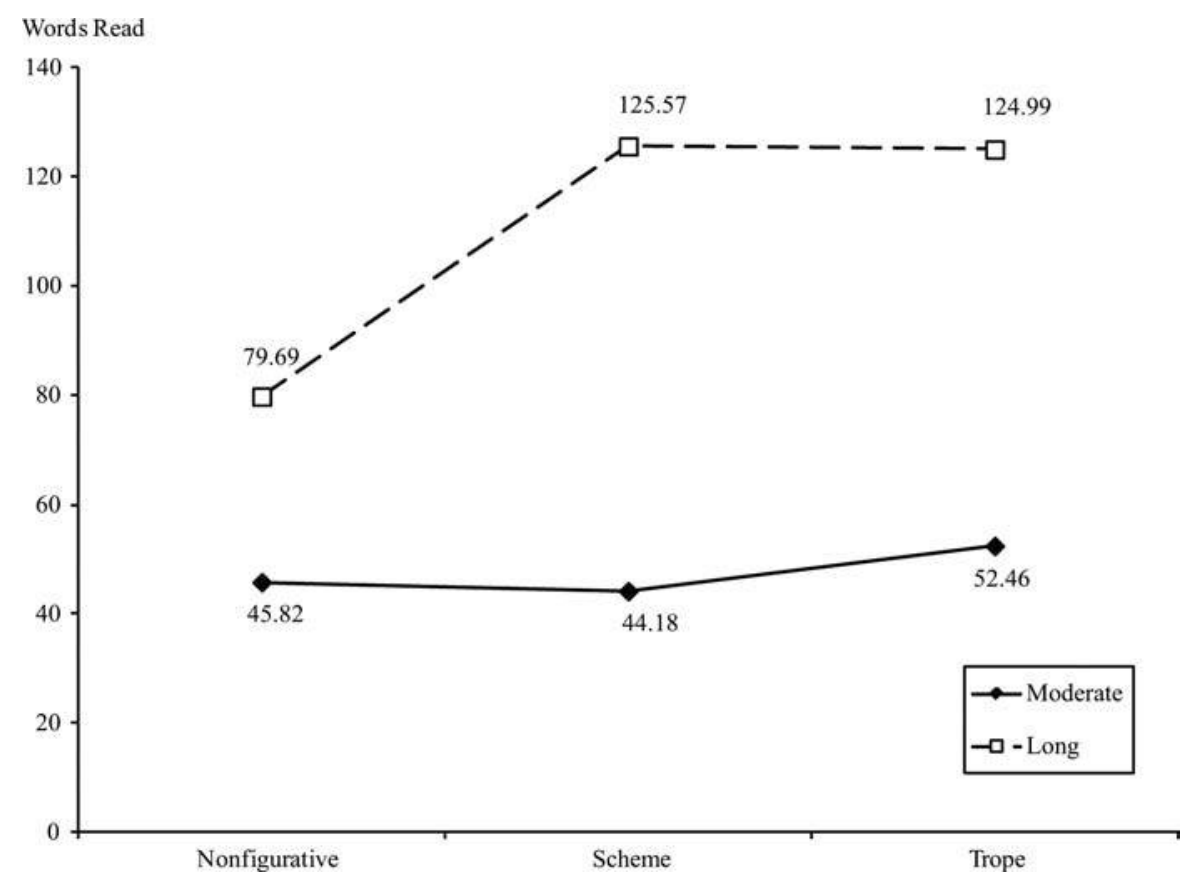

nonfigurative $\left(F_{\text {contrast }}=8.71 ; p<0.005\right)$, scheme $\left(F_{\text {contrast }}=79.37 ; p<0.001\right)$ and trope headlines $\left(F_{\text {contrast }}=66.81 ; p<0.001\right)$, comparisons demonstrate a ceiling effect with moderate copy in which participants read an average of two-thirds of the 75 words of moderate copy regardless of headline (all $F_{\text {contrast }}<0.77$; ns). However, participants read fewer of the 218 words of long copy when exposed to nonfigurative than scheme $\left(F_{\text {contrast }}=23.49 ; p<0.001\right)$ or trope headlines $\left(F_{\text {contrast }}=23.85\right.$; $p<0.001$ ).

Prior research presumes an inverse relationship between copy length and liking (Starch, 1966). This study also finds moderate copy $(M=5.74)$ produces more $\mathrm{L}_{\mathrm{ad}}$ than long copy $\left(M=5.33 ; F_{\text {contrast }}=3.98, p<0.05\right)$. Thus, holding liking constant across headlines should result in more brand awareness/persuasion for better liked moderate than long copy regardless of headline condition if liking determines rhetorical works' previously documented enhanced brand awareness/persuasion compared with nonfigurative works (see Table I).

However, headline by length interactions reported in Table III lead to $H 2$ 's rejection for brand awareness/persuasion. Multivariate and univariate analyses reveal this interaction on both brand awareness measures. Figure 3 shows greater brand recall with moderate than long copy for nonfigurative $\left(F_{\text {contrast }}=8.73, p<0.005\right)$ but no difference for trope headlines $\left(F_{\text {contrast }}=0.28\right.$, ns). Surprisingly, brand recall was greater with long than moderate copy for schemes $\left(F_{\text {contrast }}=4.30, p<0.05\right)$. Figure 4 shows greater BRBBR with moderate than long copy for nonfigurative $\left(F_{\text {contrast }}=8.16, p<0.005\right)$ but no length difference for schemes $\left(F_{\text {contrast }}=3.15, \mathrm{~ns}\right)$ or tropes $\left(F_{\text {contrast }}=0.09, \mathrm{~ns}\right)$. 


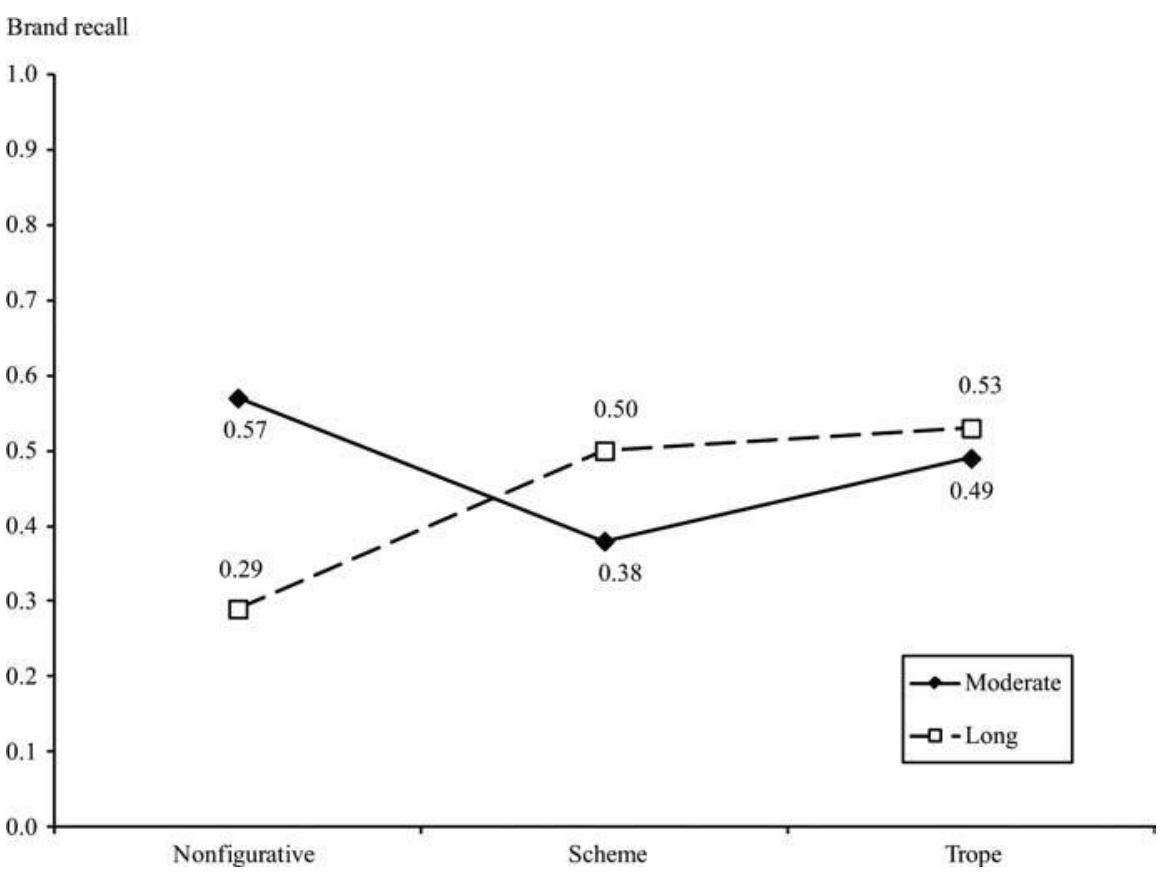

Figure 3.

Headline by copy length interaction on brand recall

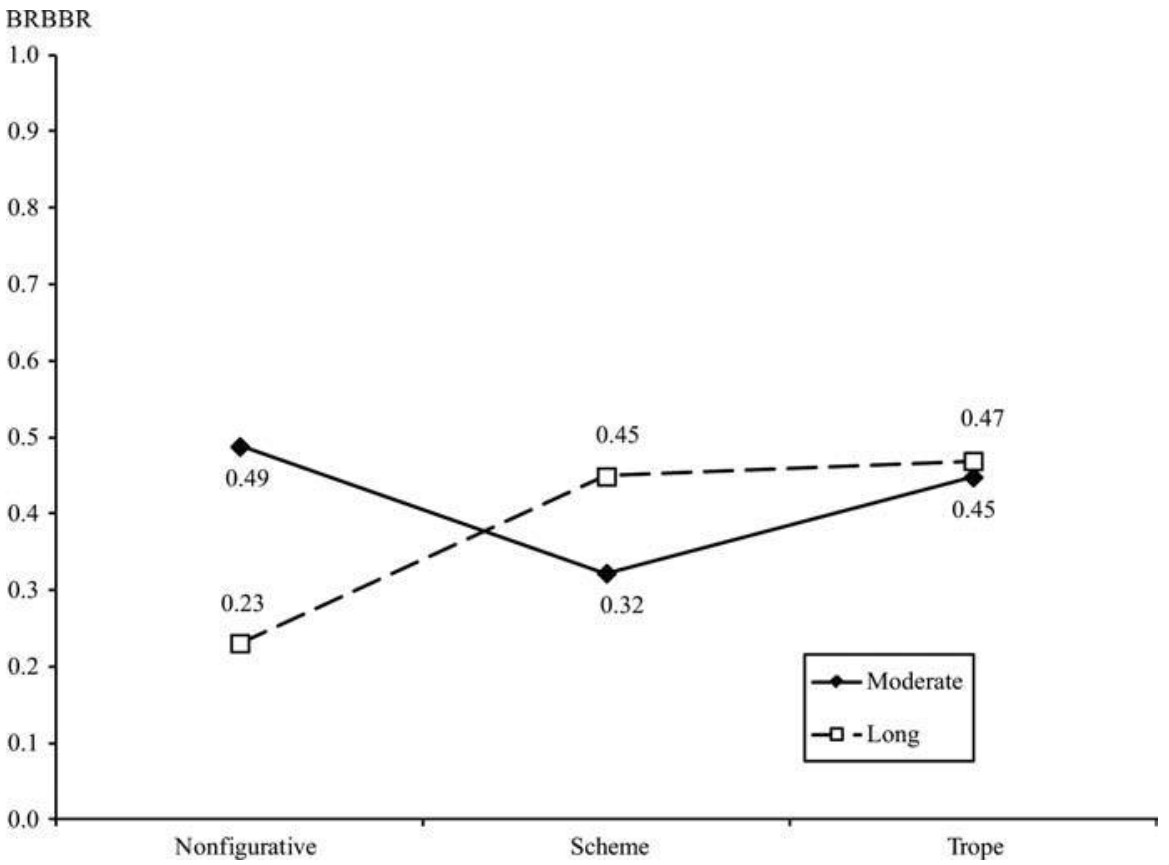

Figure 4.

Headline by copy length interaction on brand-recall-boosted brand recognition (BRBBR) 
Multivariate and univariate analyses in Table III reveal a headline by length interaction on both persuasion measures. Figure 5 shows more positive $A_{b}$ with moderate than long copy for nonfigurative $\left(F_{\text {contrast }}=11.66 ; p<0.001\right)$, but no length difference for schemes $\left(F_{\text {contrast }}=085\right.$; ns) or tropes $\left(F_{\text {contrast }}=0.32\right.$; ns). Figure 6 shows greater BAI with moderate than long copy for nonfigurative headlines $\left(F_{\text {contrast }}=12.63 ; p<0.001\right)$, but no length difference for schemes $\left(F_{\text {contrast }}=0.07 ; \mathrm{ns}\right)$ or tropes $\left(F_{\text {contrast }}=0.27\right.$; ns). It appears that consumers strive to resolve meaning openness or artful deviance associated with rhetorical headlines by exploring the ad, which weakens copy length differences on brand awareness/persuasion for rhetorical works.

The motivation of available resources through meaning openness and/or artful deviance compensates for tropes' greater resource demand recorded in the manipulation checks. Subsequent analyses to examine overall scheme-trope differences found similar brand recall and BAI ( $F_{\text {contrast' }}$ 's $<3.25$, ns). BRBBR is similar between scheme $(M=0.39)$ and trope or nonfigurative headlines $\left(F_{\text {contrast }}\right.$ 's $<$ 1.94 , ns) but tropes $(M=0.46)$ increase brand recall over nonfigurative $\left(M=0.33 ; F_{\text {contrast }}=8.73, p<0.005\right)$. Likewise, $\mathrm{A}_{\mathrm{b}}$ is similar between scheme $(M=5.94)$ and trope or nonfigurative headlines $\left(F_{\text {contrast }} \mathrm{s}<2.61, \mathrm{~ns}\right)$ but tropes $(M=6.16)$ increase $\mathrm{A}_{\mathrm{b}}$ over nonfigurative $\left(M=5.61 ; F_{\text {contrast }}=7.23, p<0.01\right)$.

\section{Discussion}

Prior research documents enhanced advertising effectiveness through rhetorical works. However, liking determines many processing, brand awareness, and persuasion effects (Bergkvist and Rossiter, 2008; MacKenzie and Lutz, 1989; Smits et al., 2006). Thus, observed effects might spuriously depend on liking differences between specific

Figure 5.

Headline by copy length interaction on brand attitude (Ab)

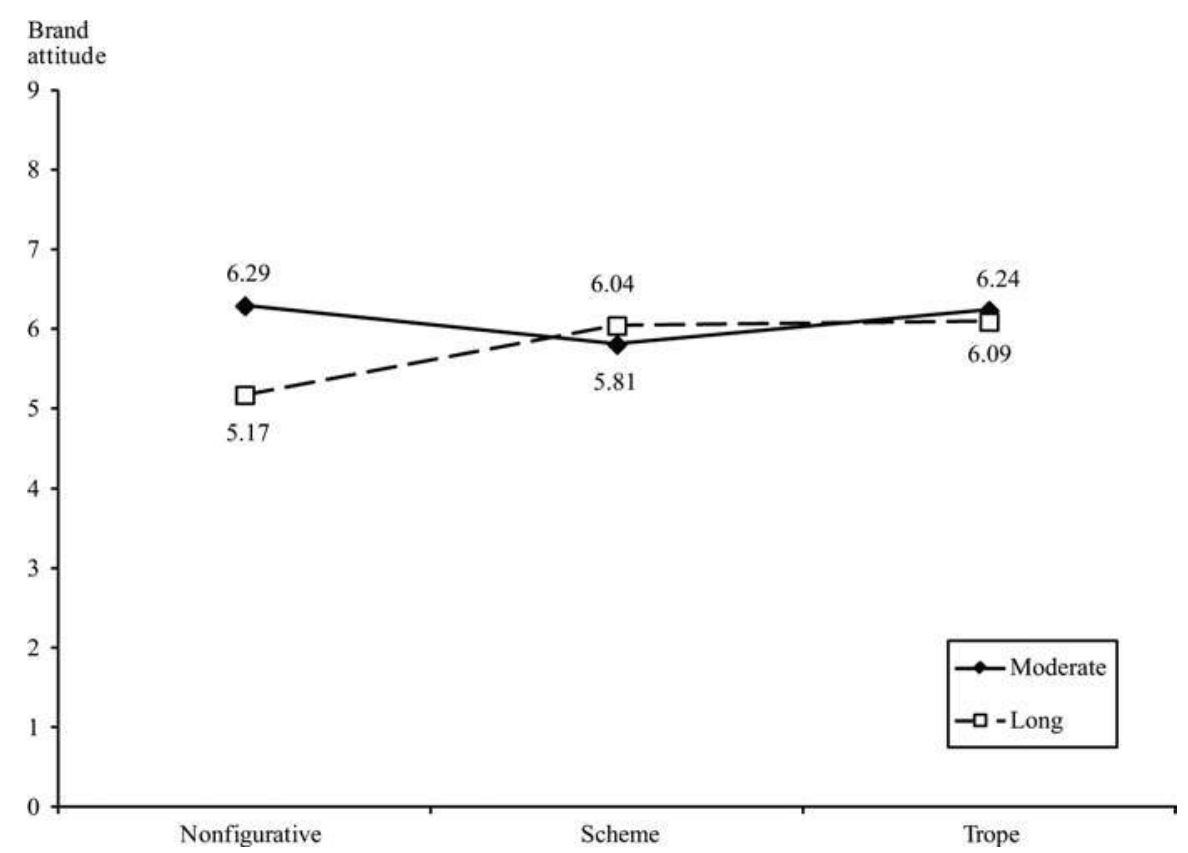




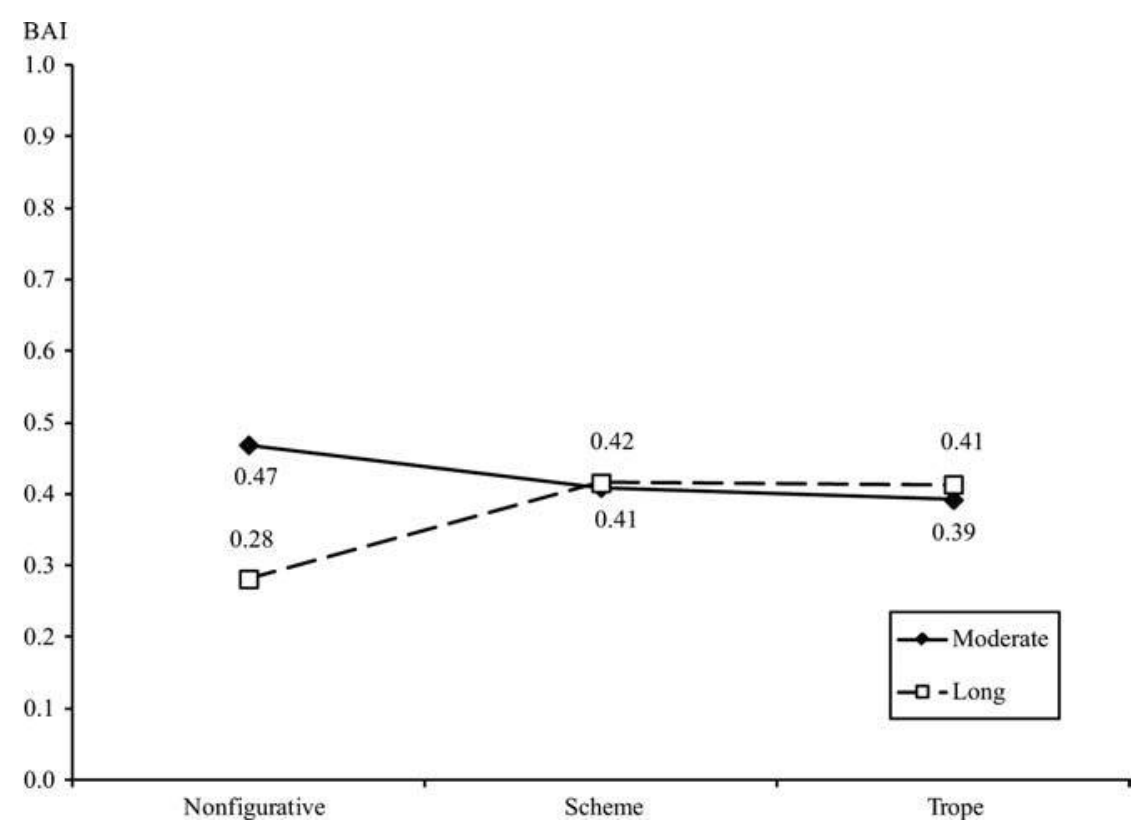

Figure 6.

Headline by copy length interaction on brand action intentions (BAI)

rhetorical and nonfigurative works used in prior research that either documented a concurrent increase in liking with rhetoric or failed to control/measure liking (see Table I).

To isolate effects attributable to liking, a study held liking constant across nonfigurative, scheme, and trope headlines with equivalent meanings. It found that processing effects (readership and elaboration) are unattributable to liking. Although words read is a different readership measure, rhetorical headlines motivated increased words read and rated processing than nonfigurative headlines regardless of involvement or copy length, consistent with previous research (Dingena, 1994; Huhmann et al., 2002; Jeong, 2008; Mothersbaugh et al., 2002). However, brand awareness and persuasion effects previously associated with rhetoric works appear more dependent on liking. Holding liking constant diminished main effects found previously when rhetoric increased liking over nonfigurative. This explains why some studies neither measuring nor controlling liking found no brand awareness/persuasion effects.

Theoretical implications. The resource-matching perspective explains non-liking-based effects of rhetorical works. Processing is optimized when resource demand equals available resources (Anand and Sternthal, 1990; Larsen et al., 2004). Involvement motivates available resources and lengthening copy increases resource demand. Results suggest rhetorical works also motivate available resources.

Interactions also support the resource-matching perspective, as do DeRosia's (2008) visual rhetoric and Brennan and Bahn's (2006) extended metaphor results between $A_{b}$ and need for cognition, which intrinsically motivates available resources. Under lower involvement, tropes encouraged greater elaboration than nonfigurative headlines regardless of copy length. Under higher involvement, rhetorical headlines increased 
processing over nonfigurative headlines only with highly resource-demanding long copy. Unlike Toncar and Munch (2001) who found greater liking and brand claims recall for tropes than nonfiguratives under lower involvement, controlling liking negated copy-point recognition differences between tropes and nonfiguratives. Toncar and Munch (2001) also found trope brand claim copy led to more positive $A_{b}$ under lower than higher involvement, but we found no involvement interaction with liking differences controlled.

Results support positive processing effect of rhetorical works found previously (Huhmann et al., 2002; McQuarrie and Mick, 1992, 1999; McQuarrie and Phillips, 2005; Mothersbaugh et al., 2002). Thus, other rhetorical properties - meaning openness, incongruity, or artful deviance - not liking motivate elaborative processing and tropes exhibit a higher degree of these properties than schemes.

Finally, controlling liking differences weakens prior trope-superiority (McQuarrie and Mick, 1999, 2003; Mothersbaugh et al., 2002) or scheme-superiority effects (McQuarrie and Mick, 2009). Among processing measures, tropes are superior to schemes only in message thoughts and copy-point recognition, but schemes are superior in advertising-style thoughts. No scheme-trope differences are evident with brand awareness or persuasion measures with liking controlled.

Practical implications of our results should assist advertisers in designing advertisements that better engage consumers, especially when longer copy is required. Words read averaged 60-70 percent of moderate copy regardless of headline. Consistent with the resource-matching perspective, additional available resources elicited by rhetorical works exceeded moderate copy's resource demand; thus, overabundant available resources did not benefit processing, but produced a ceiling effect consistent with Toncar and Munch's (2001) elaboration finding under higher involvement. However, long copy's higher resource demand decreased words read drastically (37 percent) with nonfigurative headlines even under higher involvement. Alternatively, rhetorical works in a copy-heavy advertisement maintained words read (57 percent) and elaborative processing at a level consistent with less copy. Rhetorical headlines, especially tropes, motivated more available resources than nonfigurative headlines, which better met longer copy's resource demand to the benefit of processing, awareness, and persuasion. Consequently, rhetorical rather than nonfigurative headlines could help practitioners overcome resistance to reading long copy often necessary in advertising complex products, such as new technologies, financial instruments, or health-related goods/services. By balancing copy's resource demand against greater available resources elicited by rhetorical works, advertisers can include more persuasive brand information without suffering diminished message processing. Further, if consumers process favourable arguments, preference for advertised brands, especially new brands, increases even under low involvement (Olson and Thjømøe, 2003).

Also, our results support practitioners' frequent usage of advertising rhetoric by eliminating liking as a necessary boundary condition for advertising effectiveness. Therefore, if an advertisement's rhetorical work fails to create sufficient positive affect in target recipients, it should not necessarily fail. Other rhetorical properties should benefit processing and, under high cognitive resource demand (e.g. long or technical copy), even brand awareness/persuasion.

Further, practitioners can match the type of rhetorical work to the desired advertising effect because processing focus differs. Schemes' surface-level incongruity 
focuses recipients on presentation and creative elements and encourages the most advertising-style thoughts, consistent with Mothersbaugh et al. (2002). Thus, practitioners should include schemes to attract general attention in image advertising or reminder advertising for established brands that includes other favourable creative elements (e.g. warmth appeals, celebrity endorsements, trade characters, pleasant images, etc.). Unlike Mothersbaugh et al. (2002), tropes do not increase advertising-style thoughts compared to nonfigurative headlines absent liking differences. Tropes encourage more message thoughts than schemes. Similarly, Ahluwalia and Burnkrant (2004) found tropes encouraged a message, not an advertising-style focus. As Mothersbaugh et al. (2002) suggest, we found tropes' semantic incongruity focuses consumers on brand information to resolve meaning openness, artful deviance, or other textual puzzles. Thus, practitioners should include tropes to direct consumer processing of strong brand information, unique selling points, or competitive advantages.

Consistent with Starch (1966), we observed an inverse copy length-liking relationship. As Grimes (2008) suggests, brand awareness/persuasion reflect this liking difference for nonfigurative headlines. Thus, practitioners should use creative executions, such as rhetorical works, to encourage consumers to devote more available resources to exploring advertisements and to overcome consumers' aversion to longer copy with tropes since the negative effect of longer copy found with nonfigurative headlines disappears for all brand awareness/persuasion variables. With schemes, the copy length difference disappears for BRBBR, $\mathrm{A}_{\mathrm{b}}$ and BAI.

Interestingly, contrary to copy length's relationship with liking, brand recall was greater for schemes with long versus moderate copy. The moderate copy version mentioned the brand name five times versus nine times in the long copy version; so, brand recall should be higher with long than moderate copy except that longer copy increases resource demand, which reduces processing. Without rhetorical works to encourage more available resources, brand recall decreased as copy lengthened and, hence, resource demand increased with nonfigurative headlines. Tropes overcame the length difference in brand recall. However, brand recall for schemes dropped from long to moderate copy. This indicates tedium (schemes motivated more available resources than required for moderate copy's resource demand, but available resources better matched demand with long copy) and/or interference, whereby schemes impede brand name recall.

Future research and limitations. In addition to brand recall, schemes interfere with memory for brand information. Despite the same copy points in the moderate and long copy versions, long copy produces uniformly low copy-point recognition regardless of headline. Moderate copy boosts copy-point recognition for nonfigurative and trope, but not scheme headlines. Schemes interference with brand recall and brand information memory seems consistent with research on other creative executions (i.e. sexy models or humour). For example, explicit sex appeals interfere with copy-point recall (Severn et al., 1990). Similarly, humour interferes with both copy- and brand-name recall (Gelb and Zinkhan, 1986). Schemes' apparent interference with brand-name and brand information memory warrants future investigation. In addition, this study did not explore rhetorical works that combine schemes and tropes, such as Volkswagen Jetta's "Junk in the Trunk", which employs rhyme combined with a pun as the phrase emphasizes large luggage/storage space but has a second meaning as slang for a large buttocks. To date, research has mainly examined headlines with clear scheme or trope 
distinctions. Future research should investigate the processing effects of combined executional elements, such as multiple types of rhetorical works.

Like Yorkston and Menon (2004), rhetorical works had stronger processing effects as resource demand increases. Although natural print advertisement exposure was mimicked, self-pacing is a limitation. In broadcast media, greater resource demand associated with rhetorical works, especially tropes, may benefit processing less as demand surpasses the peak of the inverted-U function between processing performance and structural properties commonly documented in experimental aesthetics (Huhmann, 2007). In radio advertisements, speech rate also impacts resource demand. Thus, future research could determine whether schemes (moderate resource demand) outperforms both nonfigurative and trope radio copy as speech rates increase. More resource-demanding tropes combined with faster speech rates may overwhelm available resources and impede advertising effectiveness.

Another limitation is the lack of tests between different levels of other rhetorical properties (e.g. meaning openness, incongruity, novelty, complexity, etc.) due to this study's focus on stringent experimental control of liking differences. Hence, future research should investigate the structural properties or mechanisms responsible for rhetorical works' impact on processing.

Finally, we open new avenues of research into the role liking plays in other creative elements associated with effective advertising. Removing liking differences allows researchers to investigate the unique impact of creative executions independent of liking's established role.

\section{Conclusion}

To rule out that advertising effects of rhetorical over nonfigurative works depend on greater liking, we held liking constant to test null hypotheses that effects previously associated with rhetorical versus nonfigurative headlines in print advertisements would be eliminated. The null hypotheses were rejected.

Previously observed processing effects are robust and unattributable to liking. Liking wields a greater influence over brand awareness and persuasion. However, rhetoric can still enhance awareness/persuasion by mitigating negative effects of advertising elements that increase cognitive resource demand (e.g. longer copy). However, prior studies' trope- or scheme-superiority is primarily an artefact of liking. Finally, we support the resource-matching perspective's viability in explaining advertising rhetoric's influence on consumers' processing, brand awareness, and persuasion.

In summary, this study extends knowledge of the usefulness of rhetorical works in print advertising beyond the view that enjoyment of the execution is solely responsible for readers' processing of an advertisement and thereby increasing brand awareness and persuasion. Our results illustrate that rhetorical works are robust motivators of both increased elaboration and readership.

\section{References}

Ahluwalia, R. and Burnkrant, R.E. (2004), "Answering questions about questions: a persuasion knowledge perspective for understanding the effects of rhetorical questions", Lournal of Consumer Research, Vol. 31 No. 1, pp. 26-42.

Anand, P. and Sternthal, B. (1990), "Ease of message processing as a moderator of repetition effects in advertising", Lournal of Marketing Research, Vol. 27 No. 3, pp. 345-53. 
Bergkvist, L. and Rossiter, J.R. (2008), “The role of ad likability in predicting an ad's campaign performance", Journal of Advertising, Vol. 37 No. 2, pp. 85-97.

Bettman, J.R., Luce, M.F. and Payne, J.W. (1998), "Constructive consumer choice processes", Iournal of Consumer Research, Vol. 25 No. 3, pp. 187-217.

Bosman, J. and Hagendoorn, L. (1991), "Effects of literal and metaphorical peruasive messages", Metaphor and Symbolic Activity, Vol. 6 No. 4, pp. 271-92.

Bowers, J.W. and Osborn, M.M. (1966), "Attitudinal effects of selected types of concluding metaphors in persuasive speeches", Speech Monograbhs, Vol. 33 No. 2, pp. 147-55.

Brennan, I.B. and Bahn, K.D. (2006), "Literal versus extended symbolic messages and advertising effectiveness: the moderating role of need for cognition”, Psvchology \& Marketing, Vol. 23 No. 4, pp. 273-95.

Celsi, R.L. and Olson, J. (1988), "The role of involvement in attention and comprehension processes", Lournal of Consumer Research, Vol. 15 No. 2, pp. 210-24.

DeRosia, E.D. (2008), "The effectiveness of nonverbal symbolic signs and metaphors in advertisements: an experimental inquiry", Psychology \& Marketing, Vol. 25 No. 3, pp. 298-316.

Diamond, D.S. (1968), "A quantitative approach to magazine advertisement format selection", Journal of Marketing Research, Vol. 5 No. 4, pp. 376-86.

Dingena, M. (1994), The Creation of Meaning in Advertising, Thesis Publishers, Amsterdam.

Fiske, S.T. and Taylor, S.E. (1991), Social Cognition, 2nd ed., McGraw Hill, New York, NY.

Gelb, B.D. and Zinkhan, G.M. (1986), "Humor and advertising effectiveness after repeated exposures to a radio commercial", Lournal of Advertising, Vol. 15 No. 2, pp. 15-20-34.

Gray, S.A. and Snyder, A. (1989), "Metaphor in advertising: effects on memory", in Gardner, M.P. (Ed.), Proceedings of the Society for Consumer Psychology, American Psychological Association, Washington, DC, pp. 85-7.

Gregan-Paxton, J., Hibbard, J.D., Brunel, F.F. and Azar, P. (2002), "So that's what that is': examining the impact of analogy on consumers' knowledge development for really new products", Psvchologv \& Marketing, Vol. 19 No. 6, pp. 533-50.

Grimes, A. (2008), "Towards an integrated model of low attention advertising effects", European Lournal of Marketing, Vol. 42 Nos 1/2, pp. 69-86.

Hayes, D.S., Chemelski, B.E. and Palmer, M. (1982), "Nursery rhymes and prose passages: preschoolers' liking and short-term retention of story events”, Developmental Psychology, Vol. 18 No. 1, pp. 49-56.

Hitchon, J.C. (1997), "The locus of metaphorical persuasion: an empirical test", Lournalism and Mass Communication Quarterlv, Vol. 74 No. 1, pp. 55-68.

Huhmann, B.A. (2007), "A model of the cognitive and emotional processing of rhetorical works in advertising”, in McQuarrie, E.F. and Phillips, B.J. (Eds), Go Figure! New Directions in Advertising Rhetoric, M.E. Sharpe, Armonk, NY, pp. 133-75.

Huhmann, B.A., Mothersbaugh, D.L. and Franke, G.R. (2002), "Rhetorical figures in headings and their effect on text processing: the moderating role of information relevance and text length", IEEE Transactions on Professional Communication, Vol. 45 No. 3, pp. 157-69.

Jeong, S. (2008), "Visual metaphor in advertising: is the persuasive effect attributable to visual argumentation or metaphorical rhetoric?", Journal of Marketing Communications, Vol. 14 No. 1, pp. 59-73. 
Ketelaar, P., van Gisbergen, M.S. and Beentjes, J.W.J. (2007), "The dark side of openness for consumer response", in McQuarrie, E.F. and Phillips, B.J. (Eds), Go Figure! New Directions in Advertising Rhetoric, M.E. Sharpe, Armonk, NY, pp. 114-36.

Larsen, V., Luna, D. and Peracchio, L.A. (2004), "Points of view and pieces of time: a taxonomy of image attributes", Journal of Consumer Research, Vol. 31 No. 1, pp. 102-11.

Leigh, J.H. (1994), "The use of figures of speech in print ad headlines", Lournal of Advertising, Vol. 23 No. 2, pp. 17-33.

Leong, S.M., Tan, S.J. and Lim, W.K. (2000), "It's only words: idiom processing, language knowledge and consumer memory of Chinese print advertisements", Lournal of Marketing Communications, Vol. 6 No. 2, pp. 73-89.

McQuarrie, E.F. and Mick, D.G. (1992), "On resonance: a critical pluralistic inquiry into advertising rhetoric", Journal of Consumer Research, Vol. 19 No. 2, pp. 180-97.

McQuarrie, E.F. and Mick, D.G. (1996), "Figures of rhetoric in advertising language", Iournal of Consumer Research, Vol. 22 No. 4, pp. 424-37.

McQuarrie, E.F. and Mick, D.G. (1999), "Visual rhetoric in advertising: text-interpretive, experimental, and reader-response analyses", Journal of Consumer Research, Vol. 26 No. 1, pp. 37-54.

McQuarrie, E.F. and Mick, D.G. (2003), "Visual and verbal rhetorical figures under directed processing versus incidental exposure to advertising", Iournal of Consumer Research, Vol. 29 No. 4, pp. 579-87.

McQuarrie, E.F. and Mick, D.G. (2009), "A laboratory study of the effect of verbal rhetoric versus repetition when consumers are not directed to process advertising", International Iournal of Advertising, Vol. 28 No. 2, pp. 287-312.

McQuarrie, E.F. and Phillips, B.J. (2005), "Indirect persuasion in advertising: how consumers process metaphors presented in pictures and words”, Iournal of Advertising, Vol. 34 No. 2, pp. 7-20.

Ma, L. (2008), "Pictorial metaphor in advertising and consumer interpretation of its cultural meaning", China Media Research, Vol. 4 No. 3, pp. 9-17.

MacLachlan, J. and Jalan, P. (1985), “The effect of pre-questions on advertising recall”, Lournal of Advertising, Vol. 14 No. 1, pp. 18-22.

MacKenzie, S.B. and Lutz, R.J. (1989), "An empirical examination of the structural antecedents of attitude toward the ad in an advertising pretest context", Lournal of Marketing, Vol. 53 No. 2, pp. 48-65.

Messaris, P. (1997), Visual Persuasion: The Role of Images in Advertising, Sage Publications, Thousand Oaks, CA.

Meyers-Levy, J. and Tybout, A.M. (1989), "Schema congruity as a basis for product evaluation", Lournal of Consumer Research, Vol. 16 No. 1, pp. 39-54.

Miniard, P.W., Bhatla, S. and Rose, R.L. (1990), "On the formation and relationship of ad and brand attitudes: an experimental and causal analysis", Lournal of Marketing Research, Vol. 27 No. 3, pp. 290-303.

Mitchell, N.A., Badzinski, D.M. and Pawlowski, D.R. (1994), "The use of metaphors as vivid stimuli to enhance comprehension and recall of print advertisements", Proceedings of the 1994 Conference of the American Academy of Advertising, University of Georgia, Athens, GA, pp. 198-205.

Mothersbaugh, D.L., Huhmann, B.A. and Franke, G.R. (2002), "Combinatory and separative effects of rhetorical figures on consumers' effort and focus in ad processing", Journal of Consumer Research, Vol. 28 No. 4, pp. 589-602. 
Munch, J.M., Boller, G.W. and Swasy, J.L. (1993), "The effects of argument structure and affective tagging on product attitude formation”, Iournal of Consumer Research, Vol. 20 No. 2, pp. 294-302.

Nelson, M.R. and Hitchon, J.C. (1999), "Loud tastes, colored fragrances, and scented sounds: how and when to mix the senses in persuasive communications", Lournalism and Mass Communication Quarterly, Vol. 76 No. 2, pp. 354-72.

Olson, E.L. and Thjømøe, H.M. (2003), "The effects of peripheral exposure to information on brand preference", Eurobean Iournal of Marketing, Vol. 37 Nos 1/2, pp. 243-55.

Pawlowski, D.R., Badzinski, D.M. and Mitchell, N. (1998), "Effects of metaphors on children's comprehension and perception of print advertisements", Lournal of Advertising, Vol. 27 No. 2, pp. 83-98.

Peracchio, L.A. and Tybout, M.A. (1996), "The moderating role of prior knowledge in schema-based product evaluation”, Lournal of Consumer Research, Vol. 23 No. 3, pp. 177-92.

Petty, R.E., Cacioppo, J.T. and Schumann, D. (1983), "Central and peripheral routes to advertising effectiveness: the moderating role of involvement”, Lournal of Consumer Research, Vol. 10 No. 2, pp. 135-44.

Roehm, M.L. and Sternthal, B. (2001), "The moderating effect of knowledge and resources on the persuasive impact of analogies", Lournal of Consumer Research, Vol. 28 No. 2, pp. 257-72.

Rossiter, J.R. and Bellman, S. (2005), Marketing Communications: Theory and Applications, Pearson Prentice Hall, Frenchs Forest.

Scott, L.M. (1990), "Understanding jingles and needledrop: a rhetorical approach to music in advertising", Lournal of Consumer Research, Vol. 17 No. 2, pp. 223-36.

Scott, L.M. (1994), "Images in advertising: the need for a theory of visual rhetoric", Lournal of Consumer Research, Vol. 21 No. 2, pp. 252-73.

Scott, L.M. and Vargas, P. (2007), "Writing with pictures: toward a unifying theory of consumer response to images", Journal of Consumer Research, Vol. 34 No. 3, pp. 223-36.

Severn, J., Belch, G.E. and Belch, M.A. (1990), "The effects of sexual and non-sexual advertising appeals and information level on cognitive processing and communication effectiveness", Lournal of Advertising, Vol. 19 No. 1, pp. 14-22.

Smits, E.G., van Meurs, L. and Neijens, P.C. (2006), "Effects of advertising likeability: a ten-year perspective”, Iournal of Advertising Research, Vol. 46 No. 1, pp. 73-83.

Stafford, E.R., Walker, B.A. and Blasko, V.J. (1996), "Headline-visual consistency in print advertisements: effects of processing and evaluation", in Corfman, K.P. and Lynch, J.G. (Eds), Advances in Consumer Research, Vol. 23, Association for Consumer Research, Provo, UT, pp. 56-62.

Starch, D. (1966), Measuring Advertising Readership and Results, McGraw-Hill, New York, NY.

Tom, G. and Eves, A. (1999), "The use of rhetorical devices in advertising”, Lournal of Advertising Research, Vol. 39, July/August, pp. 39-43.

Toncar, M. and Munch, J. (2001), "Consumer responses to tropes in print advertising”, , Lournal of Advertising, Vol. 30 No. 1, pp. 55-65.

van Enschot, R., Hoeken, H. and van Mulken, M. (2008), "Rhetoric in advertising: attitudes towards verbo-pictorial rhetorical figures", Information Design Iournal, Vol. 16 No. 1, pp. 35-45.

Warlaumont, H.G. (1995), “Advertising images from persuasion to polysemy”, Lournal of Current Issues and Research in Advertising, Vol. 17 No. 1, pp. 19-31.

Yorkston, E. and Menon, G. (2004), "A sound idea: phonetic effects of brand names on consumer judgments”, Lournal of Consumer Research, Vol. 31 No. 1, pp. 43-51. 


\section{About the authors}

Bruce A. Huhmann (PhD, University of Alabama) is an Associate Professor of Marketing at New Mexico State University. His research focuses on advertising rhetoric, information, and emotions. He has published in journals such as Journal of Consumer Research, Journal of Advertising, Journal of the Academy of Marketing Science, Journal of Marketing Communications, and International Journal of Advertising.

Pia A. Albinsson (PhD, New Mexico State University) is Assistant Professor of Marketing at Appalachian State University. Her research interests are advertising rhetoric, advertising effectiveness, community networks, socially responsible consumer behaviour, and green consumption practices. Her work has been published in Advances for Consumer Research and Journal of Consumer Behaviour. Pia A. Albinsson is the corresponding author and can be contacted at: albinssonpa@appstate.edu 